\title{
Vulnerability, beliefs, treatments and economic burden of chronic obstructive pulmonary disease in rural areas in China: a cross-sectional study
}

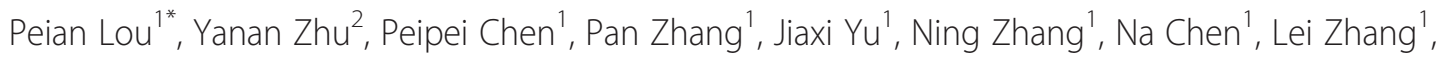
Hongmin $\mathrm{Wu}^{2}$ and Jing Zhao ${ }^{2}$

\begin{abstract}
Background: The incidence of chronic obstructive pulmonary disease (COPD) in China is very high. This study aimed to assess the vulnerability of COPD patients in rural areas outside Xuzhou City, Jiangsu province, in order to provide helpful guidance for future research and public policies.

Methods: The vulnerability of 8,217 COPD patients was evaluated using a face-to-face questionnaire to obtain information on general characteristics, awareness, beliefs, medication usage, acute exacerbation of the disease, and economic burdens. Direct economic burdens were calculated based on the questionnaire, and indirect economic burdens were estimated using local per capita income and life expectancy in 2008. The years of potential life lost were calculated using loss of life years for each age group and multiplying by the number of deaths in a given age group.

Results: Of the 8,217 patients, 7,921 (96.4\%) had not heard of COPD, and 2,638 (32.1\%) did not understand that smoking was a risk factor for COPD. No patients had used inhalers, nebulizer drugs or oxygen therapy, either regularly or sporadically. No patients had undergone pulmonary rehabilitation or surgical treatment, while 4,215 (51.3\%) took theophylline to relieve dyspnea, and 3,418 (41.6\%) used antibiotics to treat exacerbations. A total of 2,925 (35.6\%) patients had been admitted to hospital during the past year because of respiratory symptoms. The average direct and indirect economic burdens on COPD patients were 1,090 and 20,605 yuan, respectively.

Conclusions: The vulnerability of patients in rural Xuzhou to COPD was high. Their awareness of COPD was poor, their treatment during both the stable and acute exacerbation stages did not meet standards, and the economic burdens were large. Interventions are therefore needed to improve the prevention and management of COPD in this population. Further studies are required to verify these findings.
\end{abstract}

Keywords: COPD, Vulnerability, Beliefs, Treatments, Economic burden

\section{Background}

Chronic obstructive pulmonary disease (COPD) is a preventable and treatable disease [1,2], but it remains a significant public health problem. It is a major chronic cause of mortality and morbidity and has been identified as the third leading cause of mortality and morbidity worldwide [3-5]. The World Health Organization (WHO) estimated that 274 million people worldwide

\footnotetext{
* Correspondence: loupeian2004@yahoo.com.cn

'Xuzhou Center for Disease Control and Prevention, 142 West Erhuan Road, Xuzhou City 221006, Jiangsu Province, People's Republic of China

Full list of author information is available at the end of the article
}

died of COPD in 2000 [1]. An estimated 43 million men and women in China have COPD [6], and the disease mortality is about 1.6\% [7]. Management of patients with COPD must therefore become a priority in China.

COPD is characterized by airflow limitation that is not fully reversible, and a progressive decline in lung function [1]. Patients often exhibit chronic dyspnea and bronchitis, coughing, sputum production, and pathologic features of emphysema. COPD is often accompanied by exacerbation of respiratory symptoms requiring hospitalization [8]. The goals of managing stable COPD include reducing the

\section{Biomed Central}

(c) 2012 Lou et al.; licensee BioMed Central Ltd. This is an Open Access article distributed under the terms of the Creative Commons Attribution License (http://creativecommons.org/licenses/by/2.0), which permits unrestricted use, distribution, and reproduction in any medium, provided the original work is properly cited. 
frequency and severity of exacerbations, as well as controlling baseline symptoms $[1,9,10]$.

The management of patients with COPD depends upon their understanding and recognition of the disease [11-13]; they then need to seek out a general practitioner who must also recognize the condition [14]. However, current management of COPD is primarily based on hospitalized cases in urban districts [15,16], and little attention has been paid to community-based cases in other areas.

Vulnerability refers to the susceptibility of a population to risks, reflected in the likelihood and extent of population health losses caused by certain factors or changes to the health-care system [17]. Vulnerability can influence people's competence, increase their susceptibility to disease, and prolong recovery [18]. The cognitive vulnerability of COPD patients is affected by personal factors, social environment, medical history, and many other factors. Personal factors include a lack of knowledge of methods for the prevention and control of COPD, poor lifestyle, attitude, and high-risk behaviors. The social environment includes social support, availability of information, health care, economic aspects, and other factors. To evaluate the vulnerability of a population, it is necessary to identify the factors that lead to these aspects of vulnerability. Studies of the extent of cognitive vulnerability in patients with COPD can provide a scientific basis for developing targeted control measures.

This study therefore aimed to evaluate the vulnerability of patients with COPD, with respect to their comprehension of the disease, treatments and economic burdens, and to provide scientific evidence to improve the prevention and management of COPD in China and other countries.

\section{Methods \\ Subjects}

Tongshan County, in the Xuzhou City region of Jiangsu province, has 28 townships and 1.14 million inhabitants. From a total of 1.10 million health records screened by the end of 2007, 24,641 cases of COPD were uncovered according to the COPD diagnosis and treatment guidelines criteria (revised 2007) [19]. The patients enrolled in the study are listed in Figure 1. According to the Global Initiative for Chronic Obstructive Lung Diseases (GOLD), COPD can be divided into levels I-IV [20].

\section{Questionnaire design}

We designed a vulnerability questionnaire based on previously published domestic and foreign literature [21-23], which included information on aspects including epidemiology, prevention, treatment, and rehabilitation. The survey instrument consisted of 75 items and was divided into five domains: demographic data (10 items), cognition of COPD (15 items), behaviors (5 items), disease management (10 items), qualities of life (25 items) and economic burdens (10 items).

\section{Measurements of general data}

The 8,217 patients with COPD were interviewed faceto-face in their homes. Information on age, gender, current employment status, level of education, cigarettesmoking status, marital status, physical activity, family history of COPD and other conditions were obtained using the designed questionnaire. The interview also obtained data on the cost of hospitalizations, outpatient costs, outpatient accommodation, in-home treatment costs, and the costs of long-term medication regimens including drugs purchased at the patient's own expense, self-medication drugs, and costs related to lost productivity and lost employment in the last year (by examining the patient's hospital records and records from township and village clinics). Hospital accommodation costs included the costs of patient transportation and meals, their escorts, and employment costs paid to caregivers.

\section{Calculation of economic burdens}

Direct economic burdens were calculated using the questionnaire. Indirect economic burdens were estimated using local per capita income and life expectancy for 2008. In order to estimate the risk of premature death, the number of years of potential life lost (YPLL) as a result of COPD per 100,000 people was assessed. According to the local life expectancy statistics, the reference survival age was set at 70 years, and the loss of potential life was defined as between 70 years and the age of the patient at death. The age composition of China's population census report of 2000 was used to adjust the composition of the population in 2008 in Tongshan County. The YPLL was calculated as follows: YPLL $=\Sigma$ (ai $\times \mathrm{di})$, where $a \mathrm{i}=$ loss of life years for a certain age group, and $\mathrm{di}=$ the number of deaths in a given age group. Average YPLL = YPLL/deaths [24].

This study was carried out between March 2008 and March 2009 in the rural area surrounding Xuzhou City in Jiangsu province, China. The study was approved by the Ethics Committee of the Xuzhou Center for Disease Control and Prevention, and the Regional Ethical Vetting Board, Xuzhou, China. Informed consent (verbal and written in English, translated to Igbo when necessary) was obtained from all participants.

\section{Statistical analysis}

Data analysis was performed using the Statistical Package for Social Science (SPSS) version 13.0. Numerical variables were expressed as means \pm standard deviations (SD). For 


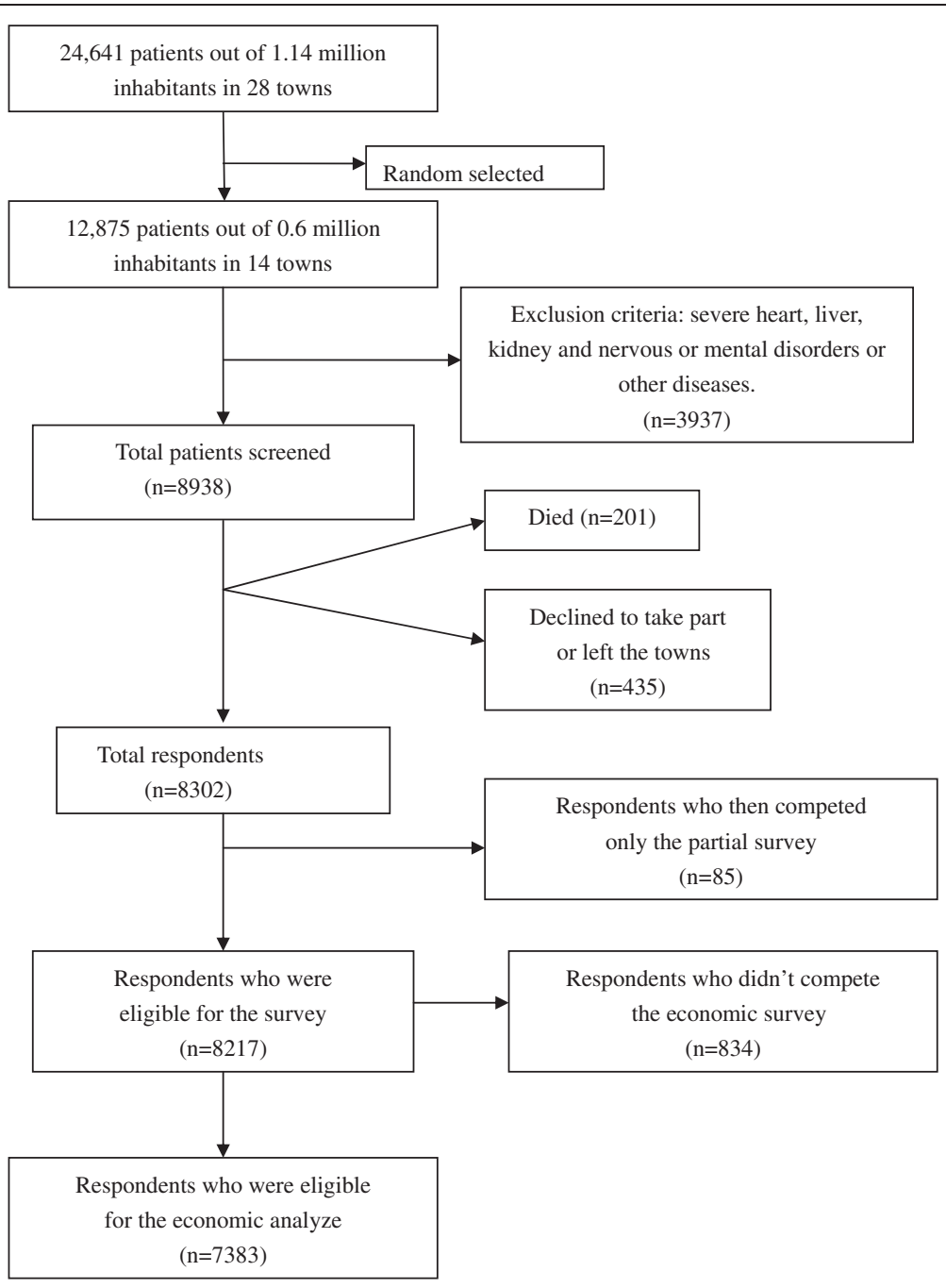

Figure 1 Sample construction.

categorical variables, the percentages of patients were calculated.

\section{Results}

\section{General characteristics}

A total of 8,302 questionnaires were sent out and all were returned. Of these, 8,217 were complete and valid, giving a response rate/compliance rate of $99.0 \%$. There were 3,930 male patients and 4,287 female patients (Table 1). Patient ages ranged from 36-84 years (mean \pm SD, 61.3 \pm 14.3 ). Patients between 55 and 75 years of age accounted for 63.4\% of the total. According to the GOLD classification criteria, 1,216 patients with COPD were classified as stage I (14.8\%), 3,435 as stageII(41.8\%), 2,161 as stage III (26.3\%), and 1,405 as stage IV (17.1\%).

\section{Cognitive vulnerability}

Among all the patients, 7,921 (96.4\%) had never heard the term 'COPD', and most of them thought they had contracted chronic bronchitis or bronchial asthma. The cognitive vulnerabilities are shown in Table 2. Although most patients were concerned about their health, 6,163 (75.0\%), had taken no appropriate measures, such as preventing cold, maintaining a regular vaccination schedule or taking globulin injections. However, 93.9\% of patients said that they were willing to change their behaviors (including quitting smoking and undergoing rehabilitation or physical training) to delay development of the disease. Only a very small number of patients had no opinion or were unwilling to change their unhealthy behaviors.

\section{Vulnerability to disease management}

The local health administration had not implemented any health-education programs for COPD patients, such as quitting smoking and maintaining a reasonable diet. Of the total, 649 (7.9\%) patients did not wish to accept treatment because they thought their condition was 
Table 1 Basic feature of COPD patients

\begin{tabular}{|c|c|c|}
\hline Variable & $N$ & (\%) \\
\hline \multicolumn{3}{|l|}{ Sex } \\
\hline male & 3,930 & 47.8 \\
\hline female & 4,287 & 52.2 \\
\hline \multicolumn{3}{|l|}{ Age (years) } \\
\hline$<40$ & 620 & 7.6 \\
\hline $40 \sim$ & 2,566 & 31.2 \\
\hline $60 \sim$ & 4,297 & 52.3 \\
\hline $80 \sim$ & 734 & 8.9 \\
\hline \multicolumn{3}{|l|}{ Marital status } \\
\hline unmarried & 172 & 2.1 \\
\hline married & 5,890 & 71.7 \\
\hline divorced & 43 & 0.5 \\
\hline widowed & 2,112 & 25.7 \\
\hline \multicolumn{3}{|l|}{ Living arrangement } \\
\hline live alone & 1,018 & 12.4 \\
\hline live with spouse & 4,547 & 55.3 \\
\hline live with children & 2,315 & 28.2 \\
\hline Others & 337 & 4.1 \\
\hline \multicolumn{3}{|l|}{ Education } \\
\hline illiterate & 4,665 & 56.8 \\
\hline primary school & 1739 & 21.2 \\
\hline junior school & 1,090 & 13.3 \\
\hline high school & 723 & 8.8 \\
\hline \multicolumn{3}{|c|}{ Household income per month (yuan) } \\
\hline$<300$ & 3,541 & 43.1 \\
\hline $300 \sim$ & 2,337 & 28.4 \\
\hline $500 \sim$ & 1,613 & 19.6 \\
\hline $1,000 \sim$ & 726 & 8.8 \\
\hline \multicolumn{3}{|l|}{ Disease history (years) } \\
\hline$<5$ & 796 & 9.7 \\
\hline $5 \sim$ & 1,048 & 12.8 \\
\hline $10 \sim$ & 1,928 & 23.5 \\
\hline $20 \sim$ & 3,903 & 47.5 \\
\hline $30 \sim$ & 542 & 6.6 \\
\hline
\end{tabular}

incurable, while 6,853 (83.4\%) patients wanted to accept treatment but were unable to continue to do so for financial reasons. None of the patients had used inhalers, nebulizer drugs or oxygen therapy, either regularly or sporadically. None of the patients had undergone pulmonary rehabilitation or surgical treatment, while 4,215 (51.3\%) patients took theophylline to relieve their dyspnea, and 3,418 (41.6\%) used antibiotics to treat exacerbation. Most patients underwent treatment in the village or township hospitals, but this treatment was informal and spontaneous. A total of 2,925 (35.6\%) patients had received in-patient treatment in township hospitals due to respiratory symptoms within the past year.
Table 2 Cognitive vulnerability of patients with COPD

\begin{tabular}{lll}
\hline Variable & $\mathbf{N}$ & (\%) \\
\hline Never heard the term 'COPD' & 7,921 & 96.4 \\
\hline $\begin{array}{l}\text { Told they had the following diseases, rather } \\
\text { than COPD }\end{array}$ & & \\
\hline chronic bronchitis & 6,541 & 79.6 \\
\hline emphysema & 1,241 & 15.1 \\
\hline bronchial asthma & 444 & 5.4 \\
\hline
\end{tabular}

Thought their respiratory symptoms were related to the following factors

\begin{tabular}{lll}
\hline cold & 7,240 & 88.1 \\
\hline smoking & 4,150 & 50.5 \\
\hline passive smoking & 3,106 & 37.8 \\
\hline air pollution & 3,878 & 47.2 \\
\hline exposure to cold air and change in climate & 7,691 & 93.6 \\
\hline $\begin{array}{l}\text { Believed their conditions were due to after effects of } \\
\text { the following diseases }\end{array}$ & \\
\hline chronic bronchitis & 3,920 & 47.7 \\
\hline asthma & 3,500 & 42.6 \\
\hline not knowing smoking was the main risk factor & 2,638 & 32.1 \\
\hline had taken no appropriate measures & 6,163 & 75.0 \\
\hline willing to change their bad behaviors & 7,716 & 93.9 \\
\hline
\end{tabular}

\section{Economic vulnerability}

The mean monthly per capita income of patients with COPD was $(300 \pm 165)$ yuan, while that of 3,541 (43.1\%) patients was below 300 yuan. The yearly net per capita income of a farmer in Tongshan County was 6,340 yuan in 2008 , or 528 yuan per month. The monthly per capita income of patients with COPD was $34.1 \%$ lower than that of the general population. COPD patients were unable to work for a mean of 150 days per year, while family members were prevented from working for a mean of 59 days per year. The median direct economic burden of patients with COPD in the rural areas in Tongshan County was 1,090 yuan; the medical costs of the 7,383 patients were 14,042,466 yuan, and the per capita economic burden was 1,902 yuan. The cost of outpatient services was $5,939,963$ yuan, accounting for $42.3 \%$ of the total. This was followed by hospitalization costs $(4,563,801$ yuan, $32.5 \%)$ and long-term self-financed medicines (2,878,710 yuan, $20.5 \%)$. These three categories accounted for $95.3 \%$ of COPD-related medical costs. The mean yearly per capita income of families of COPD patients was 3,600 yuan, and the mean yearly direct economic burden of one COPD patient was 1,090 yuan. COPD therefore accounted for an average of one third of the family income. Regarding the indirect economic burden, the total YPLL of patients living in Tongshan County in 2008 was 682.5 years, with an average of 3.25 years per patient, calculated using the formula, YPLL $=\Sigma(\mathrm{ai} \times \mathrm{di})$. The total number of years lost by men was 427.5 , with an average of 1.76 per person. The 
number of years lost by women was 255 years, with an average of 1.18 per person. Taking into account Tongshan farmers' yearly net per capita income (6,340 yuan) in 2008, the indirect economic loss caused by COPD was estimated at 4,327,050 yuan in total, and 20,605 yuan per capita.

\section{Discussion}

This is the first study to investigate the vulnerabilities caused by COPD in China. The results indicated high cognitive vulnerability of COPD patients in rural areas of Xuzhou. Although health education is the most effective means of improving symptoms in patients with COPD [25], no health education programs were implemented in the current survey region. Most of the patients (96.4\%) in the current study had never heard the term 'COPD' before, which was fewer than reported by Walker et al. [26]. Lung function tests and health education programs were not implemented in these patients either. These results were also consistent with the findings published by Ning et al. [27]. Tobacco smoking is the best-known causal factor associated with the development of COPD, and cessation of smoking is the only measure that can prevent the disease and modify its clinical course [28]; however, our results showed that $32.1 \%$ of patients did not know that smoking was the main risk factor for COPD. The health education system thus needs to be improved in order to raise the awareness of patients to COPD.

Medication can effectively prevent and control the symptoms of COPD, reduce the frequency and severity of exacerbations, and improve both exercise tolerance and quality of life $[29,30]$. Optimizing management of COPD patients, especially stable patients, can reduce the frequency of acute episodes [31]. Our survey showed that patients in rural Xuzhou were highly vulnerable to poor disease management. None of the stable patients received regular drug treatment, and the drug-regimencompliance rate was significantly lower than that reported by Barr et al. [32]. No individuals used inhalers or spray treatments during the acute exacerbation stage of COPD, which is well below the normal rate of inhaler use of approximately 10\%, reported by Restrepo et al. [33]. There has been a recent increase in interest in pulmonary rehabilitation programs, in line with clinical evidence clearly demonstrating reduced dyspnea, increased exercise tolerance, improved physical and emotional participation, and decreased health-care costs [34]. The current results showed that none of the patients in rural Xuzhou understood how to perform rehabilitation exercises. Influenza vaccination has been shown to prevent acute respiratory infections in patients with all severities of COPD [35], and influenza and pneumococcal vaccinations are recommended as an important risk-reduction strategy [36]. Additionally, mainly for financial reasons, patients in the current study were only hospitalized in rural hospitals, which did not provide health education.

The yearly per capita net income of Tongshan rural farmers in 2008 was 6,340 yuan, or 528 yuan per month, but the monthly per capita net income of COPD patients was $34.1 \%$ lower. The average annual income of COPD patients' families was 3,600 yuan, which was $43.2 \%$ lower than that of rural farmers. In addition, COPD patients experienced an annual direct economic burden of 1,090 yuan as a result of medical expenses, accounting for one third of their families' incomes. COPD caused a potential loss of 3.25 years of life per patient, which was higher than that reported by Fei et al. [36]. The indirect loss of income was calculated to be as high as 20,605 yuan per capita, indicating that COPD had a detrimental effect on the local population. In addition to more measurable losses, many patients lost their ability to work. This direct economic burden was less than that reported for developed countries, such as Spain, the United States and many European countries $[37,38]$. However, the annual per-capita income in these countries is also much higher than in rural China, and the COPD patients in this study might thus suffer a larger direct economic burden than patients in the U.S. and Europe.

This study was limited by focusing primarily on farmers, who do not have fixed working hours. This made it difficult to calculate accurately the number of working days lost as a result of disease. Patients also lacked formal treatment, and it was therefore difficult to obtain reliable information on medical economics.

\section{Conclusions}

Patients with COPD experienced greater cognitive vulnerability, poorer disease management, and greater disease burden than healthy people. Interventions are needed to improve the prevention and management of COPD. Further studies are needed to verify these findings.

\section{Competing interests}

The authors declare that they have no competing interests.

\section{Authors' contributions}

$\mathrm{PL}$ participated in writing the title and abstract, reviewed the text, and contributed to writing the manuscript. YN conceived the study, participated in the study design, writing the title and abstract, and editing the text, as well as in data extraction and analysis and drafting of the manuscript. PC performed literature searches, participated in writing the title and abstract and reviewing the text, and contributed to the manuscript drafts. PZ and JY conceived the study, participated in the study design and in writing the title and abstract, as well as editing the text and contributing to the manuscript drafts. NZ and NC contributed to the conception of the study, participated in the study design, and contributed to the manuscript drafts. LZ, HW and JZ were the lead authors of the original review, contributed to the conception of the study, participated in the study design, and contributed to the manuscript drafts. All authors read and approved the final manuscript. 


\section{Acknowledgments}

This research was funded by the Science and Technology Projects of Xuzhou City in 2007 (XM07C037). The researchers were independent from funding organizations. Funders of this study had no influence on the study design, data collection, analysis, interpretation of data, writing of the report, or the decision to submit the article for publication.

\section{Author details}

${ }^{1}$ Xuzhou Center for Disease Control and Prevention, 142 West Erhuan Road, Xuzhou City 221006, Jiangsu Province, People's Republic of China.

2Department of Respiratory Medicine, Affiliated Hospital of Xuzhou Medical College, 99 West Huaiai Road, Xuzhou City 221006, Jiangsu Province, People's Republic of China.

Received: 18 September 2011 Accepted: 13 April 2012 Published: 20 April 2012

\section{References}

1. Global Initiative for Chronic Obstructive Lung Disease (GOLD). Global strategy for the diagnosis, management and prevention of COPD. 2010 Available from: http://www.goldcopd.org/guidelines-global-strategyfordiagnosis-management.html. Accessed August 23, 2011.

2. Lopez AD, Shibuya K, Rao C, Mathers CD, Hansell AL, Held LS, Schmid V, Buist S: Chronic obstructive pulmonary disease: current burden and future projections. Eur Respir J 2006, 27(2):397-412.

3. Mathers $C D$, Loncar D: Projections of global mortality and burden of disease from 2002 to 2030. PLoS Med 2006, 3(11):e442

4. World Health Organization: World Health Statistics 2008. Geneva: World Health Organization 2008.

5. Chan-Yeung M, Ait-Khaled N, White N, Ip MS, Tan WC: The burden and impact of COPD in Asia and Africa. Int J Tuberc Lung Dis 2004, 8(1):2-14.

6. Zhong N, Wang C, Yao W, Chen P, Kang J, Huang S, Chen B, Wang C, Ni D, Zhou Y, Liu S, Wang X, Wang D, Lu J, Zheng J, Ran P: Prevalence of chronic obstructive pulmonary disease in China-a large population based spirometry based cross-sectional survey. Am J Respir Crit Care Med 2007, 176(8):753-760.

7. Fang XC, Wang XD, Bai CX: Burden and importance of proper management about chronic obstructive pulmonary disease in China. Int J Respir 2011, 31(7):493-497.

8. Bakerly ND, Davies C, Dyer M, Dhillon P: Cost analysis of an integrated care model in the management of acute exacerbations of chronic obstructive pulmonary disease. Chron Respir Dis 2009, 6(4):201-208.

9. Celli BR, MacNee W: Standards for the diagnosis and treatment of patients with COPD: a summary of the ATS/ERS position paper. Eur Respir J 2004, 23(6):932-946.

10. National Collaborating Centre for Chronic Conditions: Chronic obstructive pulmonary disease. National clinical guideline on management of chronic obstructive pulmonary disease in adults in primary and secondary care. Thorax 2004, 59(Suppl 1):1-232.

11. Kessler R, Stahl E, Vogelmeier C, Haughney J, Trudeau E, Lofdahl CG, Partridge MR: Patient understanding, detection, and experience of COPD exacerbations: an observational, interview-based study. Chest 2006, 130(1):133-142.

12. Rennard S, Decramer M, Calverley PM, Pride NB, Soriano JB, Vermeire PA Vestbo J: Impact of COPD in North America and Europe in 2000: subjects'perspective of confronting COPD international survey. Eur Respir J 2002, 20(4):799-805.

13. Wilkinson TM, Donaldson GC, Hurst JR, Seemungal TA, Wedzicha JA: Early therapy improves outcomes of exacerbations of chronic obstructive pulmonary disease. Am J Respir Crit Care Med 2004, 169(12):1298-1303.

14. Ulrik CS, Hansen EF, Jensen MS, Rasmussen FV, Dollerup J, Hansen G, Andersen KK, KVASIMODO II study group: Management of COPD in general practice in Denmark - participating in an educational program substantially improves adherence to guidelines. Int J Chron Obstruct Pulmon Dis 2010, 5:73-79.

15. Chen YH, Yao WZ, Kang J, Cai BQ, Zhou X, Liu Z, Chen P, Sun DJ, Zheng JP, Wang GY, Feng YL, Xu YJ, Jia Y, Lu M, Chang C, Wang XH: Attitudes and actions of chronic obstructive pulmonary disease patients on treatment: a national multi-center investigative study. Chin J Tubec Respir Dis 2010, 33(10):750-753.
16. Chai JJ, Liu T, Cai BQ: Evaluation of clinical significance of chronic obstructive pulmonary disease assessment test. Chin J Tubec Respir Dis 2011, 34(4):256-258.

17. Fan CF, Yang YF, Cao GW: Application of vulnerability appraising in constructing theoretical model for early warning of emergent public health event. Acad J Sec Mil Med Univ 2007, 28(10):116-119.

18. Chen JC, Wang AM, Wang F: Public Health Emergency Response Mechanism and Assessment System. [J] China Inspection and Quarantine 2007, 20(02):25-26.

19. Chinese Society of Respiratory Disease, chronic obstructive pulmonary disease group: Diagnosis and treatment guidelines of chronic obstructive pulmonary disease(revised edition in 2007). Chin J Intern Med 2007, 46:254-261.

20. Pauwels RA, Buist AS, Calverley PM, Jenkins CR, Hurd SS: Global strategy for the diagnosis, management, and prevention of chronic obstructive pulmonary disease. NHLBI/WHO Global Initiative for Chronic Obstructive Lung Disease (GOLD) Workshop summary. Am J Respir Grit Care Med 2001, 163(5):1256-1276.

21. Jones PW: Quality of life measurement for patients with disease of the airways. Thorax 1991, 46(9):676-682.

22. Partridge MR, van der Molen T, Myrseth SE, Busse WW: Attitudes and actions of asthma patients on regular maintenance therapy:the INSPIRE study. BMC Pulm Med 2006, 6:13.

23. Cai YY, Li ZZ, Fang ZJ: Living quality evaluation of the patients of Chronic obstructive pulmonary disease. Chin J Gen Pract 2004, 3(4):225-227.

24. CDC: Year of potential life lost before ages 65 and 85 ,United States, 1989-1990. MMWR 1992, 18:313.

25. Kunik ME, Veazey C, Cully JA, Souchek J, Graham DP, Hopko D, Carter R, Sharafkhaneh A, Goepfert EJ, Wray N, Stanley MA: COPD education and cognitive behavioral therapy group treatment for clinically significant symptoms of depression and anxiety in COPD patients: a randomized controlled trial. Psychol Med 2008, 38(3):385-396.

26. Walker SL, Saltman DL, Colucci R, Martin L: Awareness of risk factors among persons at risk for lung cancer, chronic obstructive pulmonary disease and sleep apnea: A Canadian population-based study. Can Respir J 2010, 17(6):287-294.

27. Ning S, Wanzhen Y, Hong Z: Patient's perspective of chronic obstructive pulmonary disease in Yanqing County of Beijing. Chin 1 Tuberc Respir Dis 2008, 31(3):206-208.

28. Rabe KF, Hurd S, Anzueto A, Barnes PJ, Buist SA, Calverley P, Fukuchi Y, Jenkins C, Rodriguez-Roisin R, Van-Wel C, Zielinski J: Global strategy for the diagnosis, management, and prevention of chronic obstructive pulmonary disease: GOLD executive summary. Am J Respir Crit Care Med 2007, 176(6):532-555.

29. Zhou Y, Hu G, Wang D, Wang S, Wang Y, Liu Z, Hu J, Shi Z, Peng G, Liu S, Lu J, Zheng J, Wang J, Zhong N, Ran P: Community based integrated intervention for prevention and management of chronic obstructive pulmonary disease(COPD)in Guangdong. China:cluster randomised controlled trial. BJM 2010, 341:c6387.

30. Tashkin DP: Long-acting anticholinergic use in chronic obstructive pulmonary disease:efficacy and safety. Curr Opin Pulm Med 2010, 16(2):97-105.

31. Miravitlles M: Prevention of exacerbations of COPD with pharmacotherapy. Eur Respir Rev 2010, 19(116):|19-|126.

32. Barr RG, Celli BR, Mannino DM, Petty T, Rennard SI, Sciurba FC, Stoller JK, Thomashow BM, Turino GM: Comorbidities, patient knowledge, and disease management in a national sample of patients with COPD. Am J Med 2009, 122(4):348-355.

33. Restrepo RD, Alvarez MT, Wittnebel LD, Sorenson $H$, Wettstein R, Vines DL, Sikkema-Ortiz J, Gardner DD, Wilkins RL: Medication adherence issues in patients treated for COPD. Int J Chron Obstruct Pulmon Dis 2008, 3(3):371-384.

34. Nici L, Donner C, Wouters E, Zuwallack R, Ambrosino N, Bourbeau J, Carone M, Celli B, Engelen M, Fahy B, Garvey C, Goldstein R, Gosselink R, Lareau S, Maclntyre N, Maltais F, Morgan M, O'Donnell D, Prefault C, Reardon J, Rochester C, Schols A, Singh S, Troosters T: American Thoracic Society/ European Respiratory Society statement on pulmonary rehabilitation. Am J Respir Crit Care Med 2006, 173(12):1390-1413.

35. Wongsurakiat $\mathrm{P}$, Maranetra KN, Wasi C, Kositanont U, Dejsomritrutai W, Charoenratanakul S: Acute respiratory illness in patients with COPD and the effectiveness of influenza vaccination: a randomized controlled study. Chest 2004, 125(6):2011-2020. 
36. $X u F$, Liang $Y Q$, Shen $H B, X u Y C$ : Years of potential life lost of chronic obstructive pulmonary diseases among residents in Nanjing from 1997 to 2005. Chin J Epidemiol 2007, 28(2):203-204.

37. Carrasco-Garrido P, de Miguel-Díez J, Rejas-Gutierrez J, Martín-Centeno A, Gobartt-Vázquez E, Hernandez-Barrera V, de Miguel AG, Jimenez-Garcia R: Characteristics of chronic obstructive pulmonary disease in Spain from a gender perspective. BMC Pulm Med 2009, 9:2.

38. Dalal AA, Christensen L, Liu F, Riedel AA: Direct costs of chronic obstructive pulmonary disease among managed care patients. Int $\mathrm{J}$ Chron Obstruct Pulmon Dis 2010, 5:341-349.

doi:10.1186/1471-2458-12-287

Cite this article as: Lou et al:: Vulnerability, beliefs, treatments and economic burden of chronic obstructive pulmonary disease in rural areas in China: a cross-sectional study. BMC Public Health 2012 12:287.

\section{Submit your next manuscript to BioMed Central and take full advantage of:}

- Convenient online submission

- Thorough peer review

- No space constraints or color figure charges

- Immediate publication on acceptance

- Inclusion in PubMed, CAS, Scopus and Google Scholar

- Research which is freely available for redistribution 